\title{
Research on the Training Standard of Undergraduate Engineering Education Talents
}

\author{
Lingmei Kong \\ Department of Computer Science and Technology, Guangdong Polytechnic Normal University Tianhe \\ College, Guangzhou, Guangdong, 510540
}

Keywords: training standard; undergraduate engineering; education talents

\begin{abstract}
With the rapid development of technology and industry under the background of the new industrial revolution, the quality standards for the cultivation of higher education talents in China are facing severe challenges. This article analyzes the new requirements of the new industrial revolution on the quality of engineering education personnel training from both technical and ethical perspectives, and proposes a rational return from technological alienation to technological innovation, surpassing from human dissimilation to human values; based on the talent level, the three perspectives of the model, three-dimensional goals, and strategic design of China's engineering education talents under the background of the new industrial revolution were designed. Finally, from the aspects of academic norms, quality assurance, and information disclosure, the quality standard system for engineering talent training in China was discussed. Strategy is constructed, academic standard system matrix model based on academic norms, and "PDMCA" closed feedback mechanism for the purpose of continuous improvement were established; professional certification was used as the starting point to establish external quality assurance standards equivalent to international and a social supervision system with information disclosure was established as the carrier.
\end{abstract}

\section{Introduction}

The new industrial revolution is happening. Its depth and breadth are unpredictable. It will depend on the depth and breadth of human pursuit and understanding of technology and its ethic. At present, all countries in the world are preparing for the new industrial revolution and regard engineering innovation as the fundamental force for the industrialization crisis. They are participating in a new round of engineering technological innovation in a positive attitude [1] to cultivate new technologies. Competitive advantage and industrial economic foundation. The new industrial revolution is characterized by technical competition. In essence, it is a competition for talents. "Cultivating talents of any size and type, how to train these talents is a question we must think ahead of time". The appearance of the new industrial revolution is an inevitable trend of the technological revolution and the industrial revolution. It is also an inevitable requirement for the development of society, economy, politics, and the environment today. To adapt to the new industrial revolution, to build an innovative country, and to meet the challenges of the industrial crisis, it is necessary to carry out the project. Education reforms have nurtured a number of new types of engineering talent who can adapt to the upcoming new industrial revolution. However, the new industrial revolution is beginning to show, "We can only predict the form of new industries and analyze the new needs of the engineering talent"[2], and accordingly design personnel training objectives and build a new system of quality standards.

\section{The New Industrial Revolution Puts Forward New Requirements for the Quality of Personnel Training in Engineering Education}

The root cause of modern industrialization crisis lies in the alienation of technology. Technology is the creation of human beings and has the function of "eliminating cover". However, due to the realization of negative values in the process of using technology, it has developed into an alien force 
that in turn has caused harm to humans, resulting in the resolution of the "unmasking" function of technology. Alienation is "masking" itself. The new industrial revolution is a product of human reflections on the crisis of modern industrialization and attempts to manage the industrial crisis resulting from technological alienation by creating new technologies. In the new industrial revolution of the future, renewable energy technologies and energy internet technologies, intelligent manufacturing technologies such as 3D printing, new material technologies represented by graphene and carbon fiber, modern biotechnology represented by genetic engineering, and big data The innovation and integrated development of the next generation of information technologies represented by the Group will play an important role and have a tremendous impact in the global economic transformation in the future.

At present, the new industrial revolution is in the process of being brewed and generated. "The leading technologies are still in the laboratory or even the concept stage” [3]. To complete the development from concept to actual productivity, technology innovation and industrial revolution are inseparable. Under the background of the new industrial revolution, the "formerly chasing the tail's technological innovation model is no longer effective because it loses its 'reference object', and must completely proceed from the unknown and take the path of independent innovation that focuses on original innovation."[4] The occurrence and development of the new industrial revolution in the future will require exploring new modes of technological innovation. A large number of technological innovation talents will be needed as support and guarantees. Talents will be the driving force of innovation and the carrier of innovation and technology. It can be seen that the future new industrial revolution needs support for new technologies is an irrefutable fact, but the education of engineering talents facing the new industrial revolution in the future cannot stop at the technical level. It also needs to transcend technology and focus on the subjectivity of people, to the "people-oriented" principle. The nature of education has returned.

\section{The Goal Design of Talent Training in Engineering Education under the Background of the New Industrial Revolution}

The actual demands of the new industrial revolution have given new requirements to engineering talents, paid more attention to the innovative ability and ethical and moral qualities of engineering talents, and strengthened the training of major engineering experiences, humanistic feelings, and macro-thinking abilities. According to the educational three-dimensional classification theory of education psychologist Benjamin Bloom, as well as the requirements for the qualifications of engineers and industry standards, the training objectives of engineering talents can be decomposed into knowledge goals, competency and value goals. Knowledge goals: Knowledge is the foundation of innovation. For the new industrial revolution, engineering talents should have multiple and reasonable knowledge structures. They should be proficient in professional knowledge and have broad multidisciplinary knowledge. They should use professional knowledge as the core and radiate multidisciplinary knowledge to achieve the unity of knowledge depth and breadth. In terms of professional knowledge, it is required to have a solid grasp of basic professional knowledge such as engineering basic knowledge and engineering technology principles, and to master proficiency on this basis. In terms of multidisciplinary knowledge, it involves extensively other professional knowledge and optimizes the way of thinking. This kind of interdisciplinary learning is more easily the birthplace of innovation. At the same time, we must pay attention to instrumental knowledge, master modern engineering tools and information technology tools, and adapt to the new requirements of rapid socio-economic development. Competency Quality Objectives: Competence is a kind of stock, a kind of resource that has embodied and non-embodied characteristics and its utilization degree. In response to the demand for engineering talents in China's new industrial revolution, in accordance with the requirements of higher engineering education and training objectives, engineering talents must have the capability of independent innovation. This is the overall requirement for knowledge structure, learning ability, and creative skills, and the intersection of knowledge structure. Based on sex to discover innovations. Only independent innovation can promote innovation in engineering science and technology, can we get out of the 
predicament of industrial crisis. With the advent of the "big engineering" and "system engineering" era, innovative engineering talent also needs teamwork capabilities. In addition, innovative engineering talents must be able to lead the development of engineering science and technology in their own countries and the world. They must be good at drawing on and absorbing the world's successful experiences, be able to treat the world's cultural differences correctly, have an open global perspective and an international outlook, and cross-cultural language communication and exchanges. ability.

\section{China's Undergraduate Engineering Education Personnel Training Standards.}

In January 2008, the Ministry of Education of the People's Republic of China promulgated the "Engineering Education Professional Certification Standard (Trial)" [5], which provides a general standard for undergraduate personnel training in engineering education, and from the quality evaluation, curriculum system, teaching staff, support conditions, Six aspects such as student development and management system made requirements to ensure the quality of personnel training. In the professional goals section, it is stipulated that the engineering education major must have a clear and measurable training goal and conform to the concept of school education. The basic requirements of the knowledge, ability and quality that the students must achieve are: (I) have good humanities and social science literacy, strong sense of social responsibility and good engineering professional ethics. (II) Having relevant knowledge of mathematics, natural sciences, and certain economic management knowledge required for engineering work. (III) It has the basic ability to analyze and solve engineering problems through the comprehensive use of the scientific theories and techniques. Master the necessary basic engineering knowledge and basic theory and basic knowledge of the professional; understand the frontier development status and trends of the profession; be subject to the basic training of experimental skills, engineering practice, computer application, scientific research and engineering design methods of the professional, with innovation Awareness and preliminary ability to research, develop and design new products, new processes, new technologies and new equipment. (IV) Master the basic methods of document retrieval, data query, and use of modern information technology to obtain relevant information. (V) Understand the laws and regulations related to the production, design, research and development of occupations and industries related to the profession, and be familiar with the principles, policies, laws, laws and regulations of environmental protection and sustainable development, etc. World and social influence. (VI) Has a certain ability of organization and management, strong ability of expressing and interpersonal communication, and the ability to play a role in the team. (VII) Has the correct understanding and learning ability for lifelong learning, and has the ability to adapt to development. (VIII) Ability to communicate, compete and collaborate with an international perspective and cross-cultural communication.

\section{Binary Matrix Relationship between Training Standards and Curriculum System}

In accordance with the overall thinking of the Ministry of Education to cultivate top-notch innovative talents, Huazhong University of Science and Technology has made active explorations in cultivating innovative engineering and technological talents: Qiming College, which was established jointly with the industry, has started a pilot reform and innovation in talent cultivation. In order to comply with the Ministry of Education's request for implementing the "Excellent Engineer Education Training Plan", the "Huazhong University of Science and Technology Excellence Engineer Training Program (Trial)" was formulated, and the personnel training program was determined, including basic principles, training objectives, and training targets. Talent training mode and other aspects. Among them, the training objectives are future outstanding engineers with practical abilities, entrepreneurial spirit, and international outlook; they should have the following characteristics: a broad knowledge base of humanities and social sciences and natural sciences, solid professional knowledge and skills, innovation awareness, innovative thinking, and innovation Ability and entrepreneurship, teamwork, international vision and leadership. In the implementation 
of the personnel training program, Huazhong University of Science and Technology selected major disciplines such as mechanical categories, major electrical categories, large information categories, and large-scale civil engineering rings to participate in the training program for outstanding engineers. Among them, the "Excellent Engineer" of the mechanical manufacturing and automation major aims to cultivate talents with the goal of facing the industry, facing the world, and facing the future, strengthening the awareness and ability of "self-study, active practice, international perspectives, and pursuing innovation". Future mechanical engineer with practical ability, innovative spirit, international vision and strong development potential. In order to achieve this goal, the College of Mechanical Science and Engineering formulated specific human training standards and established a binary matrix relationship between personnel training standards and curriculum systems (teaching sessions). The goal of training undergraduate talents for mechanical manufacturing and automation is described in terms of what students know, do, and do, including three major categories: knowledge and skills that should be mastered, engineering capabilities that should be possessed, and other qualities. The realization of the human resources development standards corresponding to these three categories requires different types of learning experience or curriculum content. Therefore, the classification of goals in this way will ensure that the curriculum design basis is based on various types of learning experiences that need to be integrated and their relative It's important.

\section{Conclusion}

Institutions of higher learning can refer to the general standards and professional standards of undergraduate engineering personnel training, and combine with the actual conditions of each school to formulate standard personnel training standards that meet our country's social development and international standards. With the guidance of personnel training standards, we can design corresponding curriculum systems and teaching. Link and establish the binary matrix relationship between talent training standards and curriculum system. The undergraduate engineering education personnel training standard is not only a certification tool, but also a means to guarantee the quality of personnel training. It is also a guide for the construction of the undergraduate engineering education curriculum system and teaching methods, and the promotion, application and realization of the standards are of great significance.

\section{Acknowledgements}

Quality engineering project in 2015 of guangdong province education department, Outstanding talent training plan of Computer Science and Technology, Guangdong Polytechnic Normal University Tianhe College.

\section{References}

[1] Shang Yumei. Exploring the Model of Professional Management of Professional Talents in Finance and Economics Colleges [J]. Science and Education (Physical Education Monthly), 2008(10): 96 97.

[2] Chen Chunlai, Si Rongxi. Engineering Management Professional Training Model Research [J]. Higher Engineering Education Research and Research (Suppl.), 2007:28 30.

[3] Ministry of Construction, Department of Engineering, Engineering, Engineering, Professional Guidance Committee, Engineering Management, Professional (Four-Year Course) Training Program [Z].1999.

[4] Ministry of Education of the People's Republic of China, Department of Higher Education, Ordinary High School, Division, Professional Directory, and Professional Introduction [M]. Beijing: Gao et al., 1998.

[5] Ministry of Education, Higher Education, Education Management, Professional Education, Education (Assessment) Standards [S]. 2006 